\title{
Amifostine otoprotection to cisplatin ototoxicity: a guinea pig study using otoacoustic emission distortion products (DPOEA) and scanning electron microscopy
}

Miguel Angelo Hyppolito ${ }^{1}$,José Antonio A. de Oliveira ${ }^{2}$, Ricardo Miranda Lessa ${ }^{3}$, Maria Rossato ${ }^{4}$
Key words: cisplatin, otoprotective agents, amifostine.

\section{Summary}

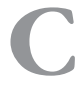

isplatin is an antineoplastic drug for cancer treatment in children and adults. The side effects of cisplatin ototoxicity are significant: irreversible bilateral hearing damage to high frequencies $(4 \mathrm{kHz}-8 \mathrm{kHz})$. Reports recognize some drugs that are associated with cisplatin to obtain an otoprotector effect. The ototoxicity mechanisms of cisplatin are related to injury of hair cell oxidation mechanism, especially of outer hair cells. Aim: Using otoacoustic emissions distortion products (DPOEA) and scanning electron microscopy we intended to verify the action of amifostine, a radioprotective drug that has well known antioxidant characteristics and otoprotector effects to cisplatin injury. Study design: Experimental. Material and Method: We used an experimental guinea pig model. The study was performed as follows: group 1: 6 animals, 12 ears, cisplatin $8.0 \mathrm{mg} / \mathrm{Kg} /$ day (IP), 3 days. Group 2: 6 animals, 12 ears, amifostine $100 \mathrm{mg} / \mathrm{Kg}$ /day (IP) and after 90 minutes, cisplatin $8.0 \mathrm{mg} / \mathrm{Kg} /$ day (IP), 3 days and group 3: 3 animals, 6 ears, amifostine $100 \mathrm{mg} / \mathrm{Kg}$ /day (IP), 3 days. Results: DPOEA were present before and after treatment in groups 2 and 3 . The normal cilium architecture of outer hair cells was supported in all cochlear turns in groups 2 and 3. We concluded that amifostine has a potential otoprotector effect against cisplatin ototoxicity and could be used in clinical trials.

${ }^{1}$ Ph.D. in Medicine, Professor, FMRP - USP (assistant physician).

${ }^{2}$ Faculty Professor, Coordinator of the Division of Otorhinolaryngology, Department of Ophthalmology, Otorhinolaryngology and Head and Neck Surgery, FMRP-USP. ${ }^{3}$ Master, Post-graduation, Division of Otorhinolaryngology, Department of Ophthalmology, Otorhinolaryngology and Head and Neck Surgery, FMRP-USP. ${ }^{4}$ Laboratory technician.

Address correspondence to: Prof. Dr. José Antonio A. de Oliveira - Área de Otorrinolaringologia do Departamento de Oftalmologia, Otorrinolaringologia e Cirurgia de Cabeça e Pescoço da Faculdade de Medicina de Ribeirão Preto da Universidade de São Paulo - Campus USP - Av. Bandeirantes 3900 Ribeirão Preto SP $14049-900$. Tel (55 16) 602-2863 - Fax (55 16) 602-2860.

Article submited on March 08, 2005. Article accepted on May 24, 2005. 


\section{INTRODUCTION}

The improvement in survival of patients with cancer by using more effective antineoplastic drugs, such as cisplatin, has favored the increase in incidence of side effects, especially in the central nervous system, kidneys and hearing system. ${ }^{1}$

Thus, different substances have been studied to try to protect subjects from these effects, without reducing antitumor activity of cisplatin.

Cisplatin causes bilateral symmetrical sensorineural loss in frequencies of 4 to $8 \mathrm{kHz}$, with association of tinnitus ${ }^{2}$.

The incidence of ototoxicity is increased as the accumulated dose of cisplatin is over $200 \mathrm{mg} / \mathrm{m} 2$ of body surface. As a result of high frequency audiometry studies, the incidence of hearing loss has increased and reached up to $70 \%$ for frequencies up to $16 \mathrm{kHz}^{3}$.

McAlpine and Johnstone, 1990, in an experimental study in guinea pigs observed damage to outer hair cells on the basal turn of the cochlea, without damage to stria vascularis ${ }^{4}$.

Studies conducted in the 90's had shown that cisplatin inhibited the activity of adenylcyclase in stria vascularis, inhibited DNA and RNA, protein synthesis and increased levels of oxygen free radicals, which are toxic to the cell. ${ }^{5}$

Ravi, 1995, showed that the cochlea might suffer affections to its anti-oxidative capacity, with reduction of cochlear glutation levels, reduction of glutation oxidase and increase in activity of catalase and dismutase superoxide enzymes. ${ }^{6}$

Different otoprotective drugs have been tested, and most of them act as cell free anti-radical, among which we can include amifostine (WR 2721, acid S - 2[3aminopropylamine] ethylphosphorothiol), developed by Walter Red Army Institute, in the 50's, to protect the toxic effects of radiotherapy, without affecting the antitumoral potential..$^{7,8}$

Yuhas and Culo, 1980, were the first ones to show that amifostine promoted a reduction in nephrotoxicity induced by cisplatin, without affecting antitumor activity, which was later confirmed by the studies conducted by Glover et al., 1986 and 1987.7,9,10

Mollman et al., 1988, showed slight reduction in ototoxicity of cisplatin in patients previously treated with amifostine ${ }^{11}$. Rubin et al., 1995, showed that there was no ototoxicity in speech frequencies in any of the patients treated with amifostine and cisplatin ${ }^{12}$.

Amifostine is converted into an active sulphidic compound, named WR1065, which acts as a cytoprotector, chelating free radicals. There is selective protection of amifostine to normal tissue cells, owing to high concentration of this compound in tumor cells. This fact is explained by reduction of alkaline phosphatase activity in tumor cells, low tumor vascularization and tumor anaerobe metabolism that causes a with very low pH medium, which does not allow intracellular entry of WR1065 because it requires a ph between 6.6 and $8.2 .^{7,8}$

In the 80's, amifostine was approved by FDA to be used in patients that received cisplatin to prevent cisplatin nephrotoxicity ${ }^{13}$. However, its use is not recommended in cases of potentially curable tumors because the influence of cisplatin in the efficacy of chemotherapy is not exactly known yet ${ }^{12,14}$.

We did not find any experimental study in the literature that had confirmed outer hair cells' protection by amifostine to the toxic effects of cisplatin.

Two experimental studies in hamsters using surface electron microscopy and brainstem evoked potential have tested the otoprotection potential of amifostine and other drugs to the effects of cisplatin. They showed that sodium thiosulfate and diethyldithiocarbamate are more effective as otoprotectors than amifostine and fosfomycin ${ }^{15,16}$.

We decided to study the otoprotective effects of amifostine to damage to outer hair cells caused by cisplatin, using functional measures through otoacoustic emission distortion product and anatomical assessment of damage caused to outer hair cells by electron scanning microscopy.

\section{MATERIAL AND METHODS}

\section{Selection of Experimental Animals}

The experimental animal selected was albino guinea pigs since they are easy to handle and the cochlea is easy to dissect, plus it is easy to infuse anesthetic drugs and experimental drugs through intraperitoneal access and they are more sensible to the effects of cisplatin. The required dose is $8.0 \mathrm{mg} / \mathrm{Kg} / \mathrm{day}$ for three consecutive days, which leads to significant cochlear affections.

Guinea pigs allow appropriate maintenance and compliance with the guidelines of care and use of laboratory animals of Institute of Laboratory Animal Resources, Commission on Life Sciences, National Research Council, National Academy Press, Washington, DC. (1996).

Animals were selected at the Central Animal Laboratory, University of Sao Paulo - Campus of Ribeirão Preto, by studying Preyer' reflex. We chose animals weighting on average 400 and 600 grams, because they were animals resistant to systemic side effects of cisplatin, with lack of appetite, weight loss, dehydration and diarrhea. ${ }^{17,18}$

After 24-hour hearing rest, animals were reassessed and we conducted manual otoscopy. Animals that presented signals of external or acute otitis media, difficult to remove cerumen, inflammatory 
affections of external auditory canal, or even very narrow canal to appropriately accommodate the probe of the otoacoustic emissions, were excluded from the study and those that presented easy to remove cerumen were maintained.

Guinea pigs were submitted to hearing screening by DPOAE in sound-proof booth and under anesthesia with Ketamine $(65 \mathrm{mg} / \mathrm{Kg})$ and Xylazin $(6.5 \mathrm{mg} / \mathrm{Kg})$. The ones that presented DPOAE in at least one of the ears were selected for the experiment.

Animals were maintained in the Animal Laboratory of the Experimental Surgery, Department of Surgery, Medical School, Ribeirão Preto-USP.

Given that it was an experiment using systemic drugs, for each tested animal we considered two cochleae and animals that presented OAE in one ear were also used.

\section{Drugs Used, Doses and Administration Route}

1. Cisplatin $(10 \mathrm{mg} / \mathrm{ml})-0.75 ; 1.5$ and $8.0 \mathrm{mg} / \mathrm{Kg} /$ day intraperitoneal access;

2. Xylazin (2g/100ml) - 6.5mg/Kg intraperitoneal access;

3. Ketamine Chlorhydrate $(50 \mathrm{mg} / \mathrm{ml})-65 \mathrm{mg} / \mathrm{Kg}-$ intraperitoneal access;

4. Amifostine $100 \mathrm{mg} / \mathrm{Kg} /$ day - intraperitoneal access.

For controlled application of tested drugs, we used 1 cc disposable syringes for each animal. For intraperitoneal application, we used disposable BD syringes size 21G1 (25 X 8 - 0.8 x 25 millimeters).

\section{Studied Groups}

Group 1: 06 animals - 12 ears - cisplatin dose of $8.0 \mathrm{mg} /$ $\mathrm{Kg} /$ day, intraperitoneal access, for three days.

Group 2: 06 animals - 12 ears - Amifostine dose of 100 mg/ $\mathrm{Kg} /$ day, intraperitoneal access and 90 minutes after, cisplatin $8.0 \mathrm{mg} / \mathrm{Kg} / \mathrm{day}$, intraperitoneal access for three days.

Group 3: 03 animals - 06 ears - Amifostine dose of 100 mg/ $\mathrm{Kg} /$ day, intraperitoneal access for three days.

\section{Auditory Functional Assessment}

\section{Distortion product otoacoustic emissions}

\section{LTD}

Equipment: ILO 92 CAE System Otodynamics

Guinea pigs were anesthetized with Ketamine Chlorhydrate and Xylazin before undergoing the tests. Before OAE, they were submitted to manual otoscopy to assess the external auditory canal and tympanic membrane, and those with signals of otitis or difficult to remove cerumen were excluded.
DPOAE was conducted before treatment and some minutes before the animals were sacrificed, following the frequency $2 \mathrm{~F} 1$ - F2 with the ratio F1:F2 $=1.22$, resolution of two points per octave.

We considered OAE as of the frequency of $1.5 \mathrm{kHz}$, because the dimensions of the external auditory canal of guinea pigs result in difficulty to detect OAE below this frequency, and the responses coincide with responses to noise.

Thus, we analyzed the frequency of $2 \mathrm{kHz}$, we provided one pure tone above and another one below it, so as the relation between them was 1.22 , automatically reaching the frequency response resulting from the relation $2 \mathrm{~F} 1-\mathrm{F} 2$ (below the assessed frequency) and 2F2-F1 (above the resulting frequency). We should also bear in mind that intensities F2 and F1 can be either similar or different. In the present study, we used intensities that were similar to 70dB SPL. The intensity of the triggering stimuli may vary from 0 to $70 \mathrm{~dB}$ SPL and it can be measured in the range 500 to 8000 Hz. $^{19}$

Resulting otoacoustic emissions are normally about $55 \mathrm{~dB}$ SPL less loud than the triggering stimulus. With $70 \mathrm{~dB}$ SPL, the generated DPOAE would range approximately from 10 to $15 \mathrm{~dB}$ SPL ${ }^{20}$.

Thus, we detected the DP gram, or audiocochleogram, in which the stimulus is a sound and a response that is also a sound and that provides information about the functions of cochlear outer hair cells responsible for the analyzed frequencies. ${ }^{21}$

In this study, what we considered as the most important were OAE in high frequencies, which qualitatively assess the functional status of outer hair cells in the basal turn of the cochlea. We considered presence or absence of DPOAE.

\section{Anatomical Assessment}

\section{Scanning Electron Microscopy (SEM)}

Equipment: Electron Microscope JEOL SCANNING MICROSCOPE - JSM 5200

Guinea pigs were sacrificed in the scheduled time after administration of drugs by intraperitoneal access and anesthesia with ether, and they were decapitated and the cochleae were removed with the bulla.

To carry out microscopic dissection of cochleae, we performed perfusion with fixation solution of glutaraldehyde at $3 \%$ at $4^{\circ}$ Celsius and maintained them in the solution for 24 hours for fixation. The following steps were carried out at the Laboratory of Electron Microscopy, Department of Morphology, FMRP-USP:

Through the round window, we injected the fixation solution of glutaraldehyde at $3 \%$ in buffer 
phosphate $0.1 \mathrm{M}, \mathrm{pH}=7.4$, for 4 hours at $4^{\circ}$ Celsius, rinsed three times for 5 minutes with the same buffer. After dissecting the cochlea, it was fixed with osmium tetroxide at $1 \%$ for 2 hours at $4^{\circ}$ Celsius and submitted to dehydration at room temperature in a growing battery of ethanol (50\%, 70\%, 90\% and 95\% - once for 10 minutes in each concentration) and absolute ethanol three times for 15 minutes. When the dehydration was over, we followed it by drying by the critical point method of $\mathrm{CO}_{2}$, in which the material was deprived from water. After being fixed in the appropriate specimen holder, the material was recovered in a vacuum chamber with gold vapors and examined under scanning electron microscopy. ${ }^{22-25}$

The results obtained by SEM, after being photographed, were analyzed through cochleograms. We used number counting of outer hair cells in the cochlear turn, in a determined photographic field, and we counted ten cells, present or absent, as shown below in Figure 1.

Data were statistically analyzed using the statistical software Statistical Package for Social Sciences - (S.P.S.S.).

We considered the comparison of results and statistically treated only data referring to basal turn, which is the most interesting aspect from the cisplatin damage perspective. However, we showed absolute values, plotted in the graph, with data referring to other cochlear turns.

\section{RESULTS}

As to anatomical assessment of group 1, treated with isolated cisplatin $(8.0 \mathrm{mg} / \mathrm{Kg} /$ day for three consecutive days) there was damage and absence of hairs in the rows of outer hair cells at the level of the basal turn, followed by turns 2 and 3. The most evident affections were seen in the basal turn, but we also observed ciliary distortion with “v" pattern disarrangement (or "w" pattern), with folded hairs or partial absence of one of the arms of the "v" pattern, as in Figure 2. At the level of the inner hair cells, we also observed affections to the hairs, with hairs present but disarranged.

In Figure 3, we can observe the comparison by stria in cochleae of groups 1, 2 and 3.

In the group previously treated with amifostine, we observed maintenance of normal architecture of outer hair cells, under scanning electron microscopy and distortion product otoacoustic emissions, which were present in all tested cochleae.

\begin{tabular}{|llll|}
\hline VV & V V V V V V V V & VV & IHC. \\
\hline V V & V V V V V V V V & V V & OHC. 1st ROW \\
\hline V V & V V V V V V V V & V V & OHC. 2nd ROW \\
\hline V V & V V V V V V V V & V V & OHC. 3rd ROW \\
\hline
\end{tabular}

Figure 1. Schematic representation of cochleogram using counting of hair cells by turn, as follows:

$\mathbf{V}=$ normal hair cell

$\mathbf{V}=$ damaged hair cell

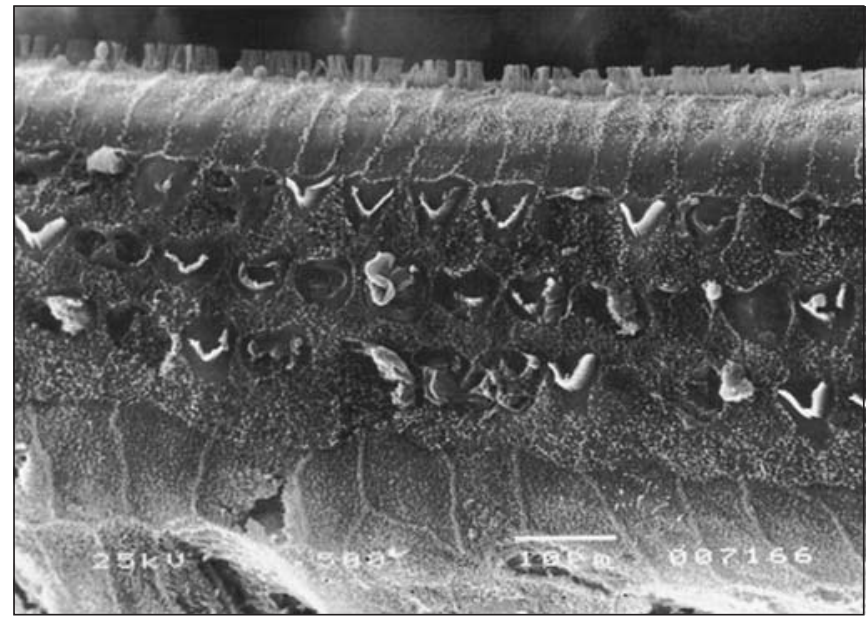

Figure 2. SEM, 1,500X magnification, cochlea of guinea pig in group

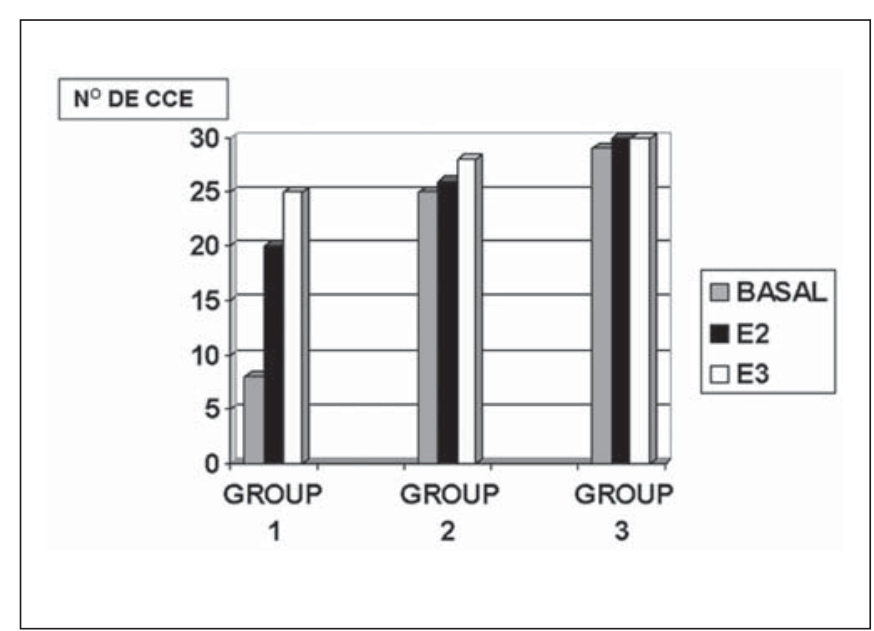

Figure 3. Mean number of outer hair cells present in the cochlear turns - basal, E2 and E3 found in groups 1, 2 and 3. 
As to statistical analysis of presented data, to compare the variable number of outer hair cells in the cochlear basal turn in groups 1, 2 and 3, we used the non-parametric test by Kruskal-Wallis. We decided in

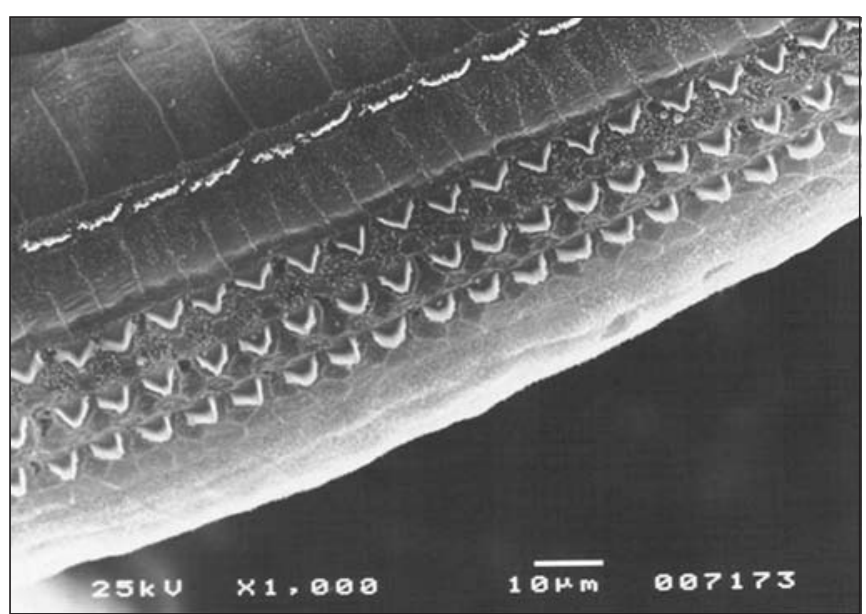

Figure 4. SEM, 1,000X magnification, cochlea of guinea pig in group 2.

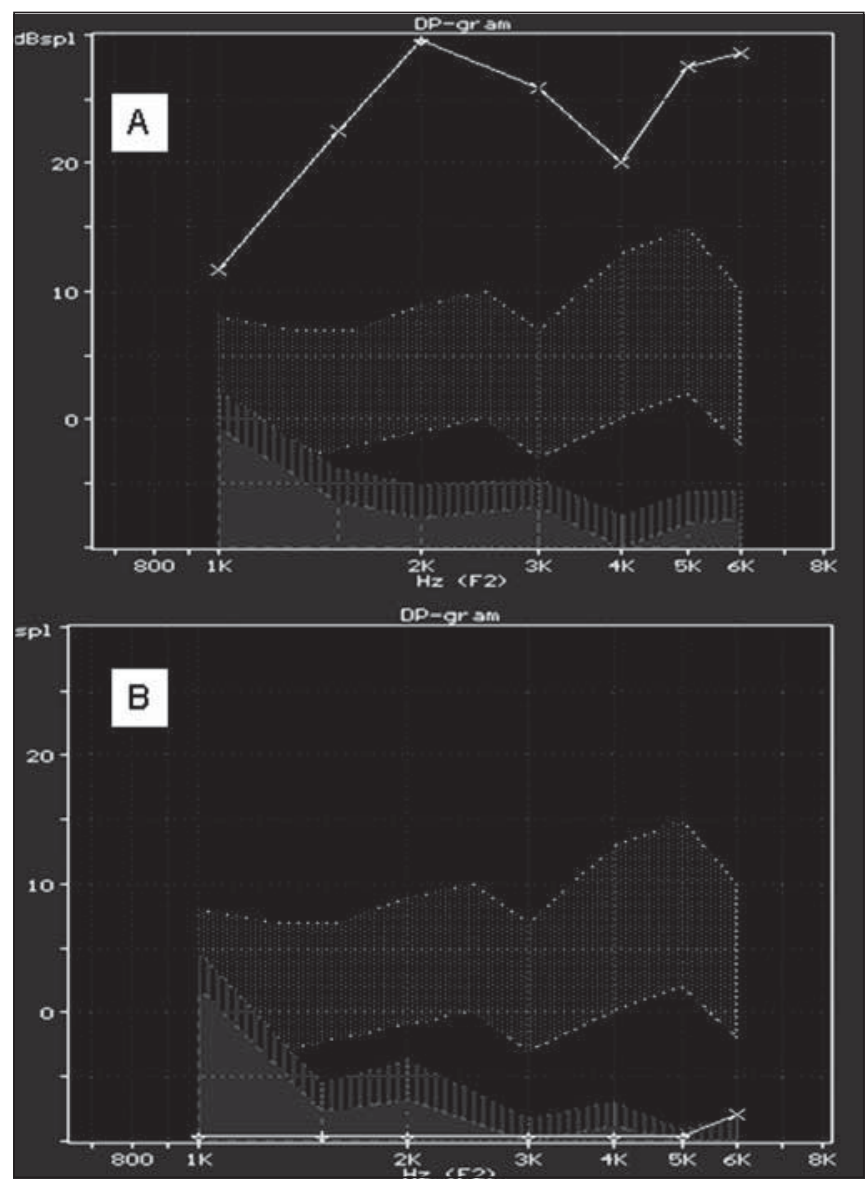

Figure 5. Distortion product otoacoustic emissions in guinea pigs treated with amifostine and cisplatin (group 2) (A) and in guinea pigs treated with cisplatin (group 1) (B). favor of a non-parametric methodology because data do not follow the normal course with this variable (Kolmogorov-Smirnoff test with $\mathrm{p}<0.001$ ). The H0 hypothesis was:

\section{H0: values of 3 groups were equivalent}

$\mathbf{X}$

H1: there is at least one pair of groups that differed significantly.

If H0 was rejected, we would use Dunn post-hoc test to check which were the detected differences.

We adopted pd0.05 as level of significance. The result of the test was $\mathrm{p}<0.001$, showing that there was significant difference between the groups. Based on Dunn's test, we detected that the number of outer hair cells in Group 1 (CISPLATIN $8.0 \mathrm{mg} / \mathrm{Kg} /$ day) was smaller than in Group 2 (amifostine $100 \mathrm{mg} / \mathrm{Kg} /$ day and CISPLATIN $8.0 \mathrm{mg} / \mathrm{Kg} /$ day), which in turn was equal to the number in group 3 (amifostine $100 \mathrm{mg} / \mathrm{Kg}$ /day).

As to variable DPOAE, we considered the comparison of presence and absence percentages. In group 1, we reached $100 \%$ absences, with group of 12 , and in groups 2 and 3, we reached $100 \%$ of presence with groups of 12 and 6 . Based on such values shown by Fisher exact test, we reached $p<0.001$ and groups 2 and 3 were equivalent and significantly different from group 1.

\section{DISCUSSION}

Amifostine has shown low toxicity and good results concerning ototoxic effects of radiotherapy as reported by Foster Nora and Siden, 1997. ${ }^{13}$

Concerning otoprotection against antineoplastic agents, especially cisplatin, Church et al. (1995), found an electrophysiological study of encephalic evoked potential in hamsters, protection by sodium thiosulfate and diethyldimethylthiocarbamate, and they did not observe effective protection against amifostine and fosfomycin ${ }^{15}$.

Kaltenbach et al. (1997) analyzed the same drugs, now associated with anatomical assessment by scanning electron microscopy and brainstem evoked potential. They found 91\% maintenance of outer hair cells with sodium thiosulfate, $68 \%$ with diethyldimethylcarbamate, $52 \%$ with fosfomycin and 45\% with amifostine.$^{16}$

In spite of these experimental data in animals, studies in humans with cisplatin for the treatment of different neoplasms have shown a tendency to nephroprotection, neuroprotection, otoprotection and myeloprotection from toxic effects of cisplatin. Foster Nora and Siden, 1997, reported that these studies comprised few subjects with different types of tumors and antineoplastic agent interactions, in addition to receiving different dosages of cisplatin. ${ }^{13}$ 
Some cancer treatment centers have included in their Guidelines the use of amifostine to prevent some toxic effects of cisplatin, in specific and dose-dependent situations, especially after authorization and standardization of its use as of 1980 by FDA, as provided by the studies by Vincent et al. (2003). ${ }^{26}$

We could observe that, in Albine guinea pigs treated with cisplatin 90 minutes after administration of amifostine, assessed functionally through distortion product otoacoustic emissions and scanning electron microscopy, there was functional and structural significant protection to acute ototoxic effects of cisplatin, different from what was reported by Kaltenbach et al. (1997), in hamsters, showing evidence of the otoprotection potential of amifostine in acute treatment with cisplatin, with doses known to be ototoxic. Such findings may justify their indication of use, as performed in different cancer centers, following the guidelines proposed by FDA (1980). ${ }^{16}$

However, its use is not recommendable in cases of potentially curable tumors because we do not know the exact influence of cisplatin in the efficacy of chemotherapy. ${ }^{12,14}$

\section{CONCLUSION}

Amifostine shows evident signals of otoprotection from ototoxic effects produced by cisplatin in albino guinea pigs.

However, its use is not recommendable in cases of potentially curable tumors because we do not know what is the exact influence of cisplatin in the efficacy of chemotherapy. ${ }^{12,14}$

\section{REFERENCES}

1. Gandara DR, Perez EA, Wiebe V, De Gregorio MW. Cisplatin Chemoprotection and Rescue: pharmacologic modulation of toxicity. Sem Oncology 1991; 18: 49-55.

2. Piel IJ, Meyer D, Percia CP, Wolfe VI. Effects of cisdiamminedichoroplatinun (NSC - 119875) on hearing function in man. Cancer Chemother Rep 1974; 58: 871-5.

3. Drescheler WA, Van Der Hulst RJ, Tange RA, Urbanus NA. Role of high-frequency audiometry in the early detection of ototoxicity. II - clinical aspects. Audiology 1989; 28(4): 211- 20.

4. McAlpine D, Johnstone BM. The ototoxic mechanism of cisplatin. Hear Res 1990; 47: 191-203.

5. Schewetzer VG. Cisplatin induced ototoxicity: the effect of pigmentation and inhibitory agents. The Laryngoscope 1993; 103 Suppl 59.

6. Ravi R, Somani SM, Rybak LP. Mechanism of cisplatin ototoxicity: antioxidant system. Pharmacology \& Toxicology 1995; 76: 38694.
7. Glover D, Glick J, Weiter C. Phase I/II Trials of WR-2721 and Cisplatin. Int. J. Radiat Oncol Biol Phys 1986; 12: 1509-12.

8. Kalaycioglu M, Bukowski R. Clinical Status of the new chemoprotective agent amifostine. Oncology 1994; 8: 15-23.

9. Glover D, Glick J, Weiter C. WR-2721 and High-dose Cisplatin: an active Combination in the Treatment of Metastatic Melanoma. J Clin Oncol 1987; 5: 574-8.

10. Yohas JM \& Culo F. Selective Inhibition of the Nephrotoxicity of Cisdichlorodiammineplatinun (II) by WR-2721 Without Altering its Antitumor Properties. Cancer Treat Rep 1980; 64: 57-64.

11. Mollman JE, Glover DJ, Hogen WM. Cisplatin Neuropathy: risk factors prognosis and protection by WR-2721. Cancer 1988; 61: 2192-5.

12. Rubin JS, Waler S, Beitter JJ, Haynes H, Razenblit A, Mcgill F, Goldeberg G, Runowicz C. Audiological findings in a phase I protocol investigating the effect of WR-2721 high-dose cisplatin and radiation therapy in patients with locally advanced cervical carcinoma. J Laryngol Otol 1995; 109: 744-7.

13. Foster Nora JA \& Siden R. Amifostine for Protection From Antineoplastic Drug Toxicity. Am J Health Syst Pharm 1997; (54) 787-800.

14. Ramath N, Lorusso P, Simon M. Phase II evaluation of cisplatin and WR-2721 of refractory metastatic breast cancer. Am J Clin Oncol 1997; 20: 368-72.

15. Church MW, Kaltenbach JA, Blakley BW, Burgio DL. The Comparative Effects of Sodium Thiosulfate Diethyldithiocarbamate Fosfomycin and WR-2721 on Ameliorating Cisplatin - induced ototoxicity. Hear Res 1995; 86 (1-2): 195-203.

16. Kaltenbach JA, Church MW, Blakley BW, McCaslin DL, Burgio DL. Comparison of five agents in protecting the cochlea against the ototoxic effects of cisplatin in the hamster. Otolaryngol Head Neck Surg 1997; 117(5): 493-500.

17. Jero J, Coling DE, Lalwani AK. The use of Preyer's reflex in evaluation of hearing in mice. Acta Otolaryngol Jul 2001; 121(5): 585-9.

18. Preyer W. Die Seele des Kindes. Leipzig: Grieben - Verlag; 1882.

19. He NJ, Schmiedt RA. Fine structure of the 2F1-F2 acoustic distortion product: changes with primary level. J Acoust Soc Am 1993; 94(5): 2659-69.

20. Rasmussen AN, Popelka GR. Osterhammel PA, Nielsen LH. Clinical significance of relative probe tone levels on distortion products otoacoustic emissions. Scand Audiol 1993; 22(4): 223 -9.

21. Lopes Filho O, Carlos R, Redondo MC. Produtos de distorção das emissões otoacústicas. Rev Brasileira de Otorrinolaringologia 1995; 61(6): 485-94.

22. Saito T, Aran J.M. Comparative ototoxicity of cisplatin during acute and chronic treatment. ORL J Otorhinolaryngol Relat Spec 1994; 56(6): 315-20.

23. Cardinaal RM, Groot JCMJ, Huizing EH, Veldman JE, Smoorenburg G.F.Dose-dependent effect of 8-day cisplatin administration upon the morphology of the albino guinea pig cochlea. Hearing Res 2000; 144: 135-46.

24. Demarco RC. Uso da gentamicina intra-timpânica para induzir ablação vestibular unilateral em cobaias. Tese de Dissertação de Mestrado FMRP-USP; 2001.

25. Oliveira JAAO, Canedo DM, Rossato M. Autodefesa contra a ototoxicidade de antibióticos aminoglicosídeos. Rev Brasileira de Otorrinolaringologia 2002; 68(1): 7-13.

26. Vincent M, Bramwell V, Moran LA, Anderson D. Use of aminfostine to ameliorate the toxic effects of chemotherapy in the treatment of cancer. Toronto(ON): Cancer Care Ontario (OCO). Practice Guideline 2003; 12-6. 